\title{
THE TRANSITION OF SON PREFERENCE: EVIDENCE FROM SOUTHEAST ASIAN COUNTRIES*
}

\author{
Nahid Tavassoli ${ }^{1}$ \\ date of paper receipt: \\ Date of sending to review: \\ date of review receipt: \\ 22.01.2021. \\ 25.01.2021. \\ 09.02.2021. \\ Review Article \\ doi: 10.247 8/eoik-2021-0010 \\ UDK 330.342(5-12):[314.332/.335:314.88
}

${ }^{1}$ Department of Economics, Texas Tech University Lubbock, TX, USA, e-mail: nahid.tavassoli@ttu.edu

\begin{abstract}
This paper explores the existence of son preference and gender-based fertility behavior among Southeast Asian mothers. Using census data of ten countries (Cambodia, China, India, Indonesia, Malaysia, Myanmar, Nepal, Philippines, Thailand, and Vietnam) over the years 1970-2014 and a sample of over 18 million observation, I show that having a first-born girl is associated with 0.16 more children in the household, equivalent to 7.2 percent rise from the mean. The marginal effects are quite robust across various specifications and subsamples. The effects are larger for countries with lower human development index and individuals with lower education. A birth cohort analysis show that the effects are significantly smaller for later cohorts implying that son preference fertility behavior has diminished over time.
\end{abstract}

\section{Keywords:}

Son Preference, Gender Discrimination, Fertility, Family Planning, Family Economics, Sex Selection, Culture 


\section{INTRODUCTION}

Do parents have a preference over the gender of their children? A relatively large body of literature in economics and sociology investigates this question as well as exploring the roots and consequences of this gender preference. This gender-discriminatory behavior may start even before the child is born. Parents spend more on prenatal care and prenatal doctor visits if the fetus is a boy (Almond \& Edlund, 2008; Bharadwaj \& Lakdawala, 2013). Mothers are more likely to abort the child and engage in sex-selective abortion if their child is a girl (Dubuc \& Coleman, 2007; Junhong, 2001; Zaidi \& Morgan, 2016). Infanticide is also another extreme method of sex-selective behavior which is shown to exist more in Southeast Asia (Miller, 1987; Suarez, 2018). The pattern of gender-based behavior persists after birth. Families spend more resource materials for their sons than their daughters (Baker \& Milligan, 2016). Boys receive more childcare time from parents, are breastfed longer, and get more vitamin supplements (Barcellos et al., 2014). Therefore, the evidence suggests that gender-based behavior exists among parents.

Gender preference may also affect the family structure. For instance, Dahl \& Moretti (2008) show that mothers who had an Ultrasound test during pregnancy are more likely to be unmarried at the time of birth if their child is a girl. Moreover, mothers with a first-born girl are more probable to be divorced, and after divorce, fathers are less likely to have custody of their child. Mothers who have a first-born girl also have significantly higher fertility rates. However, Blau et al. (2020) contradict their findings and show that for the recent cohorts and among the subpopulation of natives the effects for fertility disappear. This line of research provides more mixed evidence when examining western countries. More noticeably, several studies document the fact that among some European and specifically scandanavian countries having a first-born girl actually decreases fertility and reduces the likelihood of mother being divorced (Andersson et al., 2006; Ichino et al., 2014).

This paper reexamines the effect of a child's gender on future maternal fertility in the case of ten Southeast Asian countries, a region that is shown to have a strong and historical preference for sons. My research design is based off on the fact that the gender of the first child is quite likely exogenous. I explore the effect of the first child's gender on the future fertility of women. Using a series a census data that encompasses ten countries over the years 1970-2014, I find that a first-child girl significantly increases fertility among mothers. Having a first-child girl is associated with 0.16 additional children in the future, 4.2 percentage point higher likelihood of having two or more children, 5.9 percentage point higher likelihood of having three or more children, and 3.8 percentage point higher likelihood of having four or more children. The magnitude of the effects is economically large. For example, the effect on the number of children can be interpreted as an 8.3 percent rise from the mean of fertility over the sample period. Moreover, I show that the results are robust across specifications, subsamples, and different levels of standard error clustering. The effects are larger among countries with a higher gender inequality index, lower female education, lower female labor force participation, and lower human development index.

Improvements in assisted reproductive technologies (ART) such as In vitro fertilization (IVF) which made them available to the public at ever-decreasing costs have generated concerns and debates among policymakers as these methods could be used for sex-selective purposes. Documenting and quantifying son preference has important implications in this setting as to provide policymakers with policy suggestions for restriction in the usage of these technologies to determine and influence the sex of children. 
The rest of the paper is organized as follows. Section 2 reviews the related literature. In section 3 , I introduce the data sources and explain the sample restrictions. Section 4 discusses the empirical method and the potential threats to identification strategy. Section 5 goes over the main results. In section 6 , I check the robustness and heterogeneity of the main results. I conclude the paper in section 7.

\section{LITERATURE REVIEW}

While there is a relatively large body of literature evaluating the consequences of gender inequality only a limited number of studies explore the roots of son preference and genderbased discrimination among societies. Countries that were historically more dependent on brawn-based agriculture with higher demand for physical strength in the process of production also have higher gender inequality and son preference (Alesina et al., 2013; Doepke \& Tertilt, 2009; Hamid Noghanibehambari, Tavassoli, et al., 2020b; Qian, 2008). Higher labor-intensive home production also contributed to the observed gaps between women and men (Greenwood et al., 2005). Medical progress that could lower maternal mortality has been shown to lower the female-male gaps in education (Jayachandran, 2015; Jayachandran \& Lleras-Muney, 2009). Other cultural factors could also play a role in generating and maintaining gender inequality across countries including the Patrilocality system (Chakraborty \& Kim, 2010; Dyson \& Moore, 1983), expectations of old-age support from sons (Ebenstein \& Leung, 2010), the Dowry system (Anderson, 2007; Arnold et al., 1998; Boserup et al., 2013; Das Gupta et al., 2003a; Rao, 1993), and the Patrilineality system (Bhalotra et al., 2020; Carranza, 2012).

Several studies establish the existence of son preference and explore its various dimensions. Palloni (2017) explores the effect of a child's gender on a child's health due to parental preferential behavior. He finds that children with their mothers' preferred gender before birth have a higher body mass index and experience fewer illnesses during childhood. Muchomba \& Chatterji (2020) document that daughters of Chinese and Indian immigrants in the US compared to children of US natives have higher rates of disability and higher morbidity. Lei et al. (2017) show that sons absorb more educational resources than daughters among Chinese families. They find that being the eldest son has some educational advantage that vanishes for daughters who usually have more supervisory roles for younger siblings.

Li et al. (2016) show that the ratio of marriageable male to female in the population, the socalled marriage market sex ratio, has the potential to influence the preference of parents for their children. They find that an increase of 1 percent in the marriage market sex ratio raises the probability of having a daughter by 0.02 percentage points.

Several studies show that having a first-born girl affects the probability of divorce among women. However, Hamoudi \& Nobles (2014) show that these findings could be endogenous as the gender of a child is also influenced by the prenatal environment. They posit that if women in unstable marriages that would result in divorce regardless of their child's gender, experience stress and mental insecurity, their child is more likely to be a girl. This leaves the literature on son preference and divorce with a serious potential confounding factor.

The gender of children may also affect political opinions. Oswald \& Powdthavee (2010) document that parents who have daughters are more likely to vote for left-wing parties as these political candidates usually emphasize more on gender inequality issues. Gender also affects maternal health. Milazzo (2018) shows that Indian mothers with a first-born girl are more likely to die younger and are more prone to physical violence. She also shows that mortality 
and morbidity are larger among women with a first-child girl, an effect that amplifies after each successive female birth.

Altindag (2016) explores the effect of son preference among Turkish parents. He shows that parents are more likely to use contraceptive methods following a male birth. Parents spend more on the health environment of their children if they have a son. Female infant mortality is 1.5 percentage points lower if a male sibling is present in the household. Many other studies also document the son preference and its implications for families across different countries including US (Abrevaya, 2009; Blau et al., 2020; Dahl \& Moretti, 2008), China (Bhaskar, 2011; Das Gupta et al., 2003b; Muchomba \& Chatterji, 2020), India (Bharadwaj \& Lakdawala, 2013; Das Gupta et al., 2003b; Kishore \& Spears, 2014; Mitra, 2014; Muchomba \& Chatterji, 2020; Suarez, 2018), Pakistan (Hussain et al., 2000; Khan \& Sirageldin, 1977), Bangladesh (Asadullah et al., 2021; Kabeer et al., 2014), Nepal (Koolwal, 2007), Iran (Azimi, 2015; Foroutan \& Ashkaran, 2019), Japan (Kureishi \& Wakabayashi, 2009; Yamamura, 2013), South Korea (Choi \& Hwang, 2020), Turkey (Altindag, 2016), among other countries (Abrevaya, 2009; Almond et al., 2013; Baker \& Milligan, 2010, 2016; Bhalotra et al., 2020; Bhaskar, 2011; Blau et al., 2020; Chai Bin Park \& Nam-Hoon Cho, 1995; Chen et al., 2013; Dahl \& Moretti, 2008; Duan \& Hicks, 2020; Guo \& Zhang, 2020; Hamoudi \& Nobles, 2014; Ichino et al., 2014; Jayachandran, 2015; Jayachandran \& Lleras-Muney, 2009; Kabeer et al., 2014; Kashyap \& Villavicencio, 2016; Kaushal \& Muchomba, 2018; Kim \& Lee, 2020; Kishore \& Spears, 2014; Kureishi \& Wakabayashi, 2011; Li et al., 2016; Lundberg, 2005; Malak et al., 2019; Milazzo, 2014; Muchomba \& Chatterji, 2020; Noghani \& Noghanibehambari, 2019; NoghaniBehambari et al., 2020; H. Noghanibehambari \& Rahnamamoghadam, 2020; Hamid Noghanibehambari, Noghani, et al., 2020; Hamid Noghanibehambari, Tavassoli, et al., 2020a; Hamid Noghanibehambari \& Salari, 2020; Odimegwu et al., 2017; Pollmann-Schult, 2017; Salari et al., 2021; Suarez, 2018; Sun et al., 2019; Toranji et al., 2020; Wang et al., 2017; Yoo et al., 2017).

\section{DATA SOURCES AND SAMPLE CONSTRUCTION}

Our primary data is a series of census data extracted from Minnesota Population Center (2020). It contains information on parental characteristics including education, school attendance, employment status, labor force participation, marital status, and age. The structure of the data enables us to locate the children of parents who are present at the household during the survey. Since the main focus is fertility, I exclude males from the data. I then link each child to its mother's location in the household. I restrict the sample to include mothers in their primary age of fertility, i.e. between 18 and 45 year-olds. Since children may leave households for many reasons (including education, work, marriage, etc.), I restrict the sample to mothers whose first child in the household is at most 12 years old. However, in Appendix Table A-6, I show that the main results are quite robust to this cut-off age. The final sample consists of 10 countries, 40 sample-years, 45 years, and 18,932,205 observations (Appendix Table A-1, Appendix Table A-2, Appendix Table A-3, and Appendix Table A-4 reports cross tabulation by year, summary statistics for countries below median of gender inequality index, summary statistics for countries above median of gender inequality index, and cross tabulation by birth cohort, respectively). I also use a series of country characteristics including GDP per capita, extracted from World Bank (2020), female labor force participation, human development index, education, and gender inequality index, extracted from Human Development Reports (2020). 
Table 1. Tabulation of Countries in the Final Sample

\begin{tabular}{lll}
\hline Country & Freq. & Percent \\
\hline Myanmar & 518,490 & 2.74 \\
Cambodia & 301,590 & 1.59 \\
China & $4,334,546$ & 22.90 \\
India & 442,351 & 2.34 \\
Indonesia & $6,807,423$ & 35.96 \\
Malaysia & 117,139 & 0.62 \\
Nepal & 680,425 & 3.59 \\
Philippines & $3,013,092$ & 15.92 \\
Vietnam & $2,477,388$ & 13.09 \\
Thailand & 239,761 & 1.27 \\
\hline Total & $18,932,205$ & 100.00 \\
\hline
\end{tabular}

Table 1. shows a cross-tabulation of the observations by country. In addition, Figure 1 shows the geographic distribution of the data across the world. Table 2 reports a summary statistics of the final sample. The average number of children is 1.9 and about 59.27 percent of mothers have at least two children in the sample. Figure 2 shows the geographic distribution of countries based on their quantiles of maternal mortality rates, human development index, female labor force participation, and gender inequality index.

Table 2. Summary Statistics

\begin{tabular}{|c|c|c|c|c|c|}
\hline Variable & Observations & Mean & Std. Dev. & Min & Max \\
\hline Number of Children & $18,932,205$ & 2.2185 & 1.2645 & 1 & 9 \\
\hline Age & $18,932,205$ & 31.9165 & 6.284 & 18 & 45 \\
\hline Birth Cohort & $18,932,205$ & 1967.6621 & 11.5485 & 1925 & 1996 \\
\hline Age of Eldest Child & $18,932,205$ & 9.1856 & 5.1133 & 1 & 18 \\
\hline Sex of First Child (girl=1) & $18,932,205$ & 0.4817 & 0.4997 & 0 & 1 \\
\hline Dwelling: Owned & $18,932,205$ & 0.4702 & 0.4991 & 0 & 1 \\
\hline Dwelling: Rented & $18,932,205$ & 0.0932 & 0.2907 & 0 & 1 \\
\hline Dwelling: Missing & $18,932,205$ & 0.4366 & 0.496 & 0 & 1 \\
\hline Father Absent & $18,932,205$ & 0.043 & 0.2028 & 0 & 1 \\
\hline School Attending & $18,932,205$ & 0.0116 & 0.1071 & 0 & 1 \\
\hline Ever School Attended & $18,932,205$ & 0.4485 & 0.4973 & 0 & 1 \\
\hline Education less than Secondary & $18,932,205$ & 0.7677 & 0.4223 & 0 & 1 \\
\hline Education Secondary University & $18,932,205$ & 0.229 & 0.4202 & 0 & 1 \\
\hline Education Missing & $18,932,205$ & 0.0032 & 0.0569 & 0 & 1 \\
\hline Is Employed & $18,932,205$ & 0.4036 & 0.4906 & 0 & 1 \\
\hline Employment Missing & $18,932,205$ & 0.3661 & 0.4817 & 0 & 1 \\
\hline Labor Force Participation & $18,932,205$ & 0.4295 & 0.495 & 0 & 1 \\
\hline Labor Force Missing & $18,932,205$ & 0.3661 & 0.4817 & 0 & 1 \\
\hline Number of Children $\geq_{2}$ & $18,932,205$ & 0.6671 & 0.4712 & 0 & 1 \\
\hline Number of Children $\geq 3$ & $18,932,205$ & 0.3162 & 0.465 & 0 & 1 \\
\hline Number of Children $\geq_{4}$ & $18,932,205$ & 0.1402 & 0.3472 & 0 & 1 \\
\hline $\begin{array}{l}\text { GDP per Capita (Constant } 2005 \\
\text { US\$) }\end{array}$ & $18,932,205$ & 2140.5039 & 898.1501 & 500.2064 & 7974.251 \\
\hline Gender Inequality Index & $18,932,205$ & 0.3726 & 0.127 & 0.168 & 0.488 \\
\hline Maternal Mortality Rate & $18,932,205$ & 115.0032 & 67.8419 & 29 & 250 \\
\hline \%Secondary Education & $18,932,205$ & 58.6732 & 16.8866 & 15.1 & 76 \\
\hline $\begin{array}{l}\text { Female Labor Force Participation } \\
\text { Rate }\end{array}$ & $18,932,205$ & 56.8293 & 11.0983 & 20.5 & 82.8 \\
\hline
\end{tabular}


Figure 1. Distribution of Data Coverage

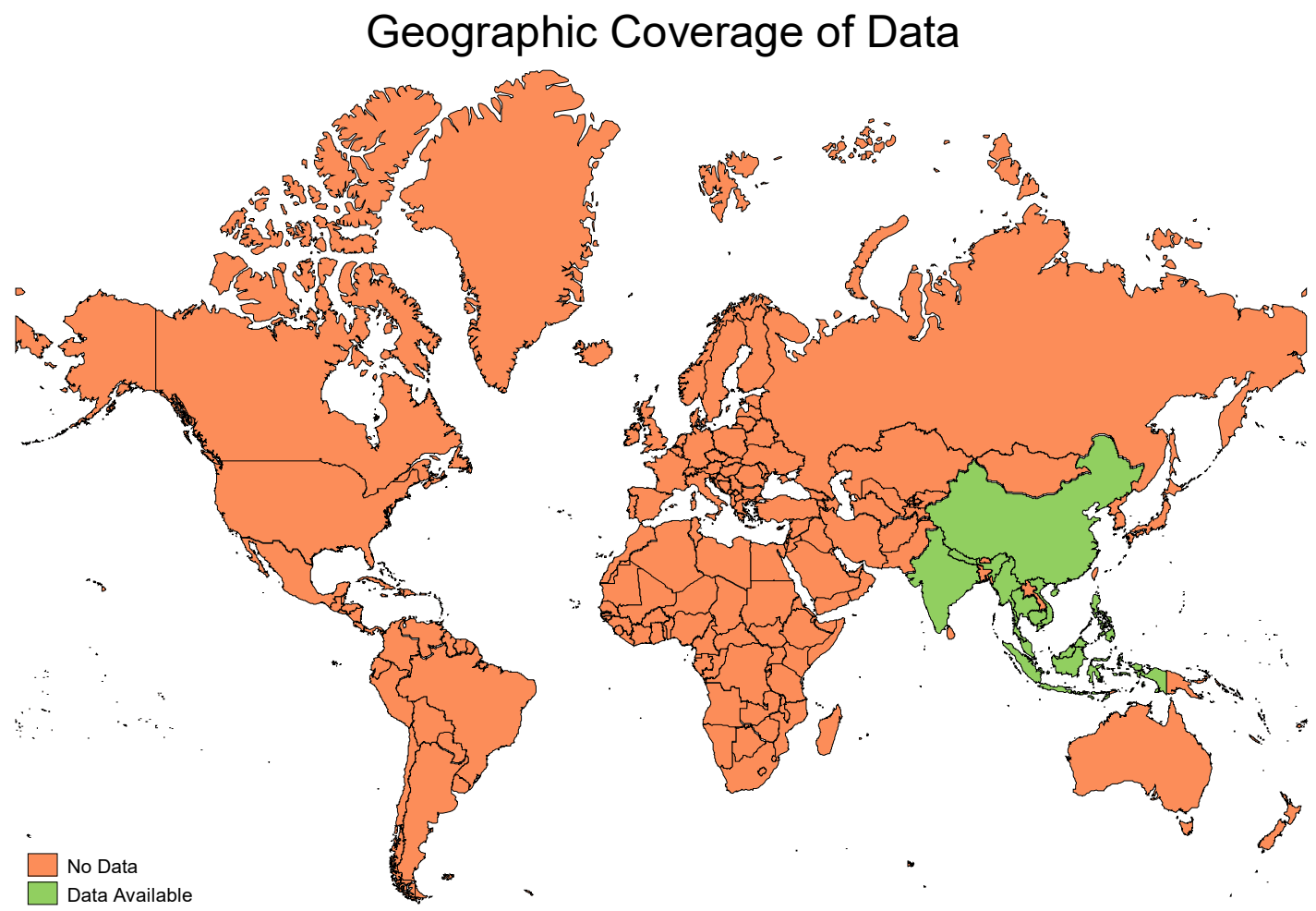

Figure 2. Distribution of Countries based on Below/Above Median of Countries' Characteristics

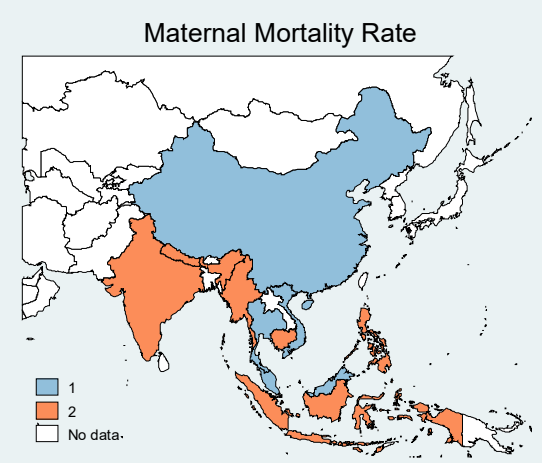

Female Labor Force Participation

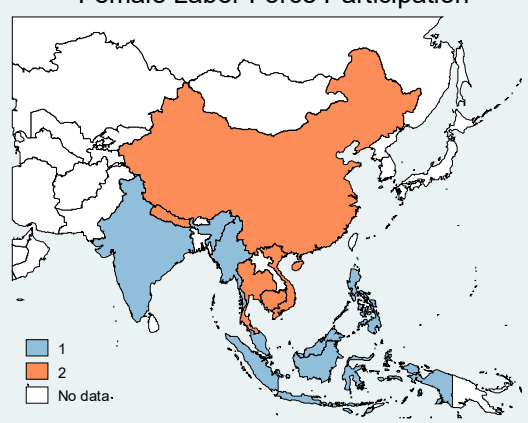

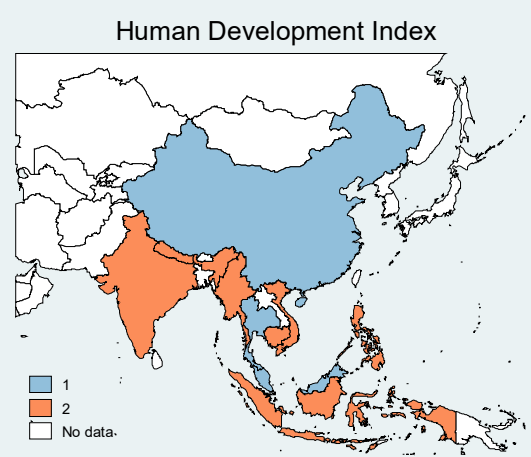

Gender Inequality Index

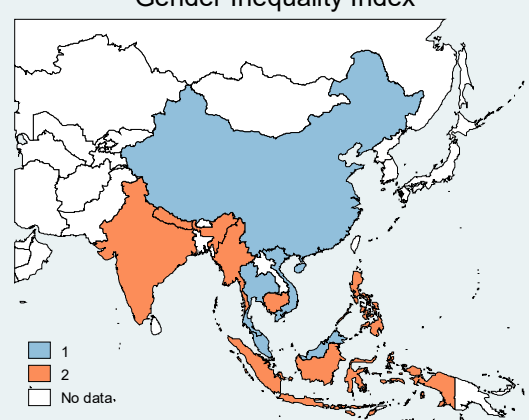


Figure 3. Distribution of First Child Girl across Birth Cohorts and Countries

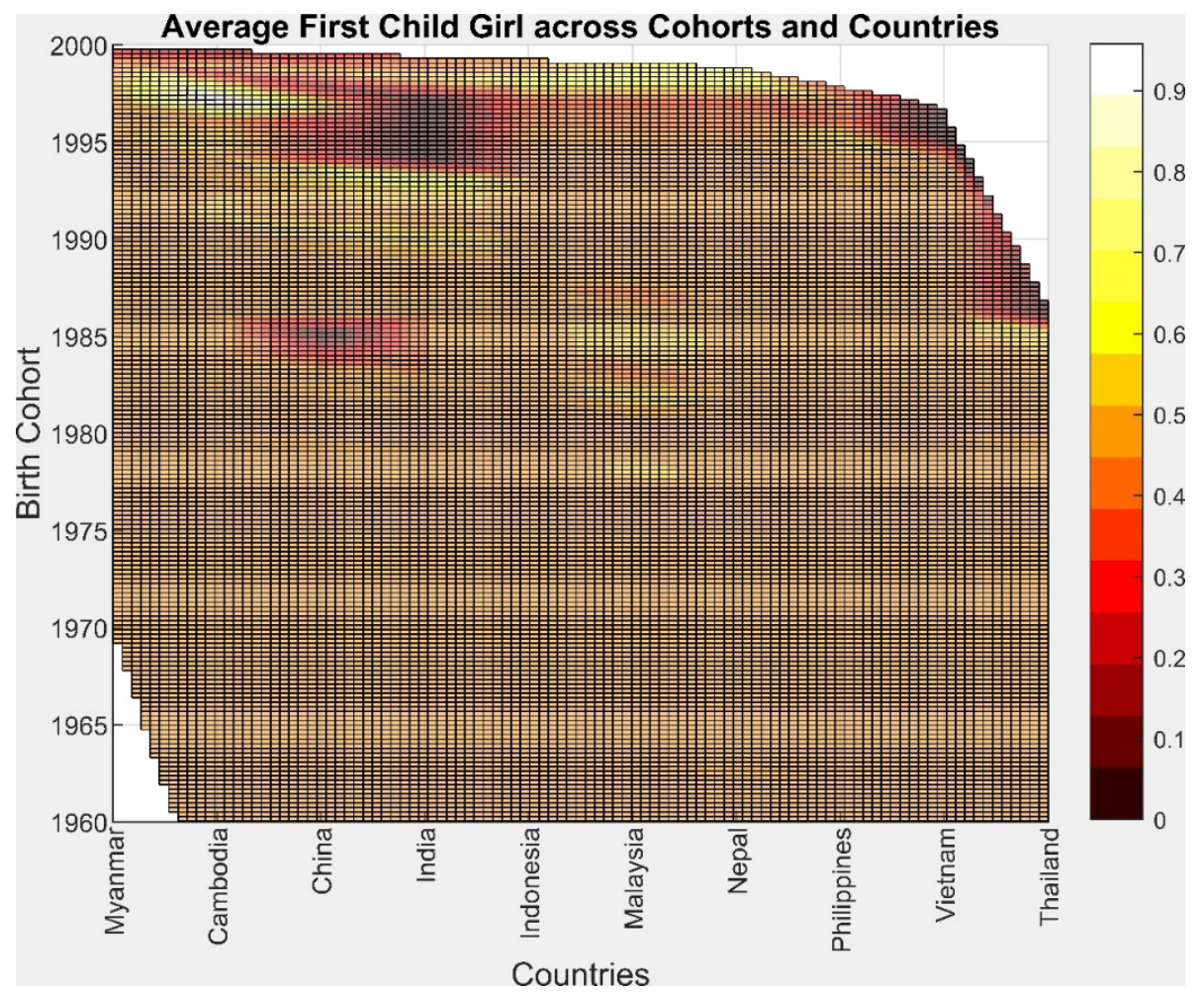

\section{EMPIRICAL STRATEGY}

To explore the effect of the first child's gender on a mother's future fertility, I apply different specifications of the following form:

$$
y_{i r t}=\alpha F G_{i t}+\beta X_{i t}+\xi_{r}+\zeta_{t}+\gamma_{r t}+\varepsilon_{i r t}
$$

Where $y$ is the mother $i$ in sub-national region $r$ observed at year $t$. In $X$, I include a series of parental characteristics: dummies for education, employment status, a cubic in age, labor force status, and school attendance. The parameters $\xi, \zeta$, and $\gamma$ represent the sub-national region, year, and regionby-year fixed effects. The region-by-year fixed effects absorb all the socioeconomic characteristics that may affect fertility and could vary by time. $F G$ is the first-child girl dummy that equals one if the first child of the mother is a girl and zero otherwise. Therefore, the coefficient of interest is $\alpha$ which can be interpreted as the effect of the first-child girl on the total number of children and likelihood of having more than 2, 3, and 4 children. I weight the regressions using personal weights provided by (Minnesota Population Center, 2020). All standard errors are clustered at the subnational region level. However, I show the robustness of the results to alternative clustering levels in Appendix Table A-5. Finally, $\varepsilon$ is a disturbance term.

The simple idea behind equation 1 is to compare the fertility behavior of mothers who have a firstborn girl to the fertility behavior of mothers with a first-born boy. The underlying assumption behind this empirical method is that the outcomes of mothers with a first-born girl follows the same path and is determined by the same influences as those mothers with a first-born boy except for the fact that they had a girl as their first child. Although this is the primary assumption in the bulk of studies on son preference it could be violated for one specific reason. Families with son preference, who would have otherwise kept their baby if it was a boy, may engage in prenatal 
sex-selective abortion or postnatal sex-selective infanticide when they find out the gender of the fetus or the newborn is a girl. In the presence of sex-selective abortion, I observe sonbiased families who have a first-child boy and have less fertility because of having a boy. This generates a spurious correlation in the estimations and causes the coefficients to be biased upwards. Although previous studies rule out this fact at least for the first-born child (Barcellos et al., 2014; Bharadwaj \& Lakdawala, 2013; Blau et al., 2020) it is important to keep that in mind when interpreting the findings.

Another concern is that the first child's gender is clustered in regions or birth cohorts for unobserved socioeconomic reasons or genetic attributes. I show the distribution of the firstchild girl variable across countries and birth cohorts in Figure 3. There is no visual evidence that the sex of the first child is highly skewed for specific regions or birth cohorts.

I focus on the gender of the first child rather than the sex composition of children for one important reason. As previous studies show, the gender of the first child could also influence family structure. Parents with a first-born girl are more likely to be unmarried and divorced. Single-parent households also have lower fertility rates (Dribe et al., 2017). Mothers may have lower fertility after a first-child girl not because of not having a son preference but because of being divorced and having fewer resources to support more pregnancies. This fact creates a sample selection issue in the child-gender and fertility relationship.

\section{MAIN RESULTS}

The main results of this paper are reported in Table 3 for different specifications and outcomes. For each outcome, I first show the effects for specifications that include region fixed effects, year fixed effects, and parental controls. Then, I add region-by-year fixed effects in the following columns. The marginal effects and the standard errors are very robust and similar across specifications. ${ }^{1}$ In the full specification of fertility effects (column 2), having a firstchild girl is associated with 0.16 additional children, equivalent to a 7.2 percent rise from the mean of fertility in the sample (reported in the fourth row). Moreover, having a first-born girl is associated with 4.2, 5.9, and 3.8 percentage points higher likelihood of having two or more children, three or more children, and four or more children, respectively. Comparing with the mean of the respective variables, these marginal effects are equivalent to 19.6, 24.08, and 21.5 percent rise from the mean.

As mentioned in section 4, women are more likely to be divorced or unmarried at the time of the birth of their first child is a girl. Also, the marital status is a confounding factor in fertility estimations as married mothers have higher fertility rates because of having more resource materials available to them. Although I control for the marital status of mothers I cannot control for unobserved features related to the marital status that cannot be captured by the marital dummies. To see whether this fact is driving the main results, I use equation 1 and restrict the sample to married mothers whose spouse is present in the household and I am able to locate the location of the spouse in the data. These results are reported in Table 4. Since the mean of the outcomes are different in the two tables, I focus on the percentage effects to compare the magnitude of the coefficients. Having a first-child girl is associated with a 6.4 percent rise from the mean total number of children which is quite comparable to the 7.2 percentage effect in Table 3. The percentage change from the mean for the number of children at least 2,3, and 4 are 7.2, 23.5, and 39.1, respectively. These changes are comparable to the percentage effect in Table 3 except for the number of children more than 4 which shows a relatively larger effect in the sample excluding married mothers. However, in both sample, all marginal effects are statistically significant at 1 percent level and economically large.

\footnotetext{
${ }^{1}$ The results, available upon request, are also very robust to including country fixed effects instead of region fixed effects, and is similar to the main results when I add region-by-birth-cohort, birth-cohort-by-year, and, birth-cohort-by-year fixed effects.
} 

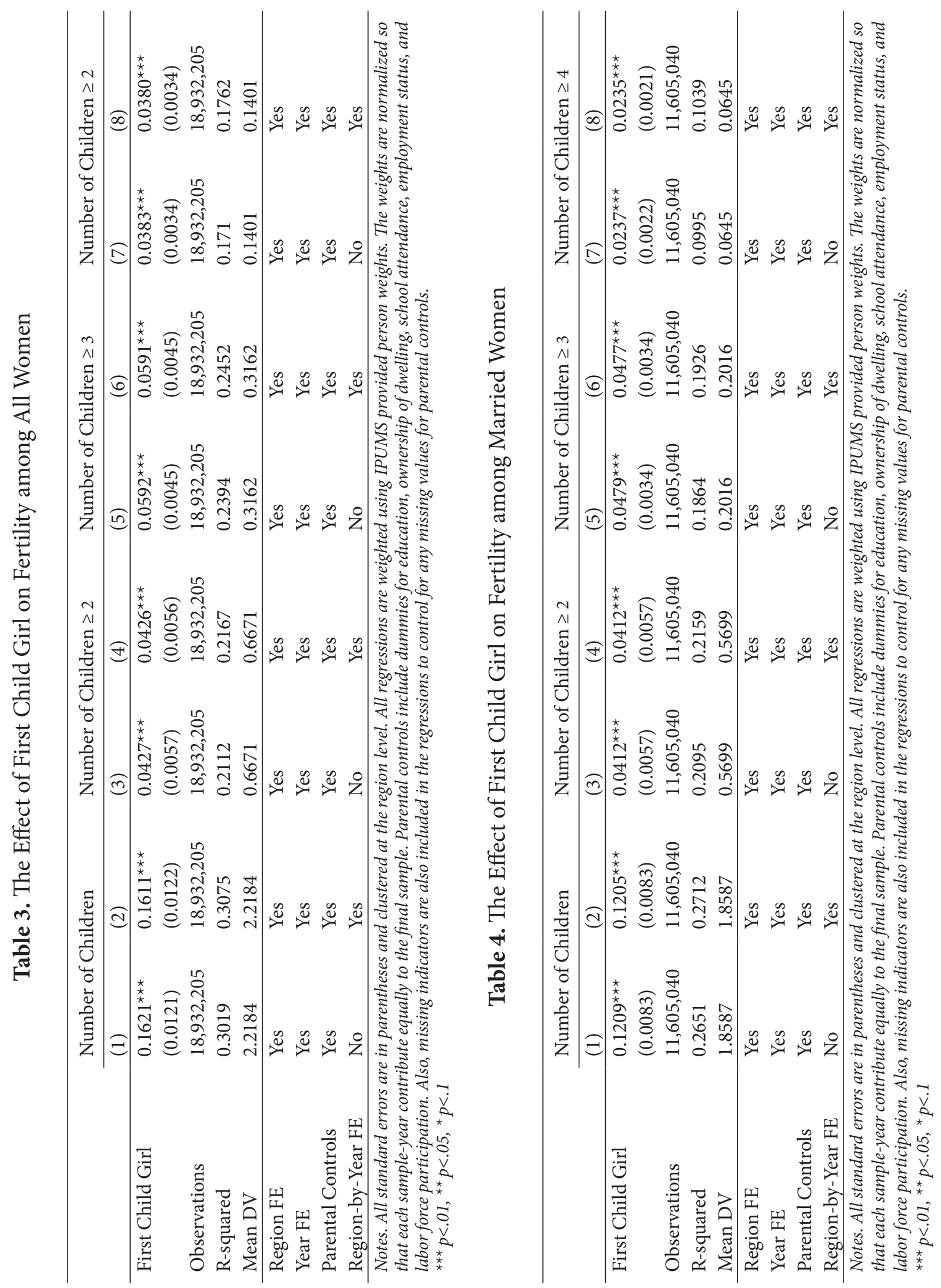


\section{ROBUSTNESS AND HETEROGENEITY}

This section explores the robustness of the main results across subsample. In so doing, I split the sample based on the quantiles of the country's characteristics. I use two indices that partly capture the cultural factors in the country as culture is shown to be correlated with son preference and female-male gaps in outcomes (Bauer \& Riphahn, 2007; Bhalotra \& Rawlings, 2013; Fernández, 2013; Fernandez \& Fogli, 2009, 2009; Fernández \& Fogli, 2006; Noghanibehambari, Tavassoli, et al., 2020a, 2020b). These indices include the Gender Inequality Index (GII) and Human Development Index (HDI) both provided by the Human Development Reports of the United Nations Development Program. The results are reported in Table 5 and Table 6. Both marginal effects and percentage changes imply that countries with higher GII and lower HDI have higher son preferences. For instance, having a first-child girl among countries above the median of GII is associated with 0.19 more children (a rise of 9.4 percent from the mean) while for countries below the median of GII this effect is 0.14 (a rise of 6.1 percent from the mean).

Previous studies also show that education and labor force participation of women is associated with some cultural norms and social attributes that may also affect their son-preference behavior (Fernandez \& Fogli, 2009; Noghanibehambari, Tavassoli, et al., 2020b). Therefore, I split the sample based on quantiles of female education and labor force participation. The results are illustrated in Table 7 and Table 8, respectively. Note that the sample split is based on individual characteristics reported in the data rather than the country characteristic criteria in Table 5 and Table 6 . Higher educated females and those active in the labor force reveal fewer son preferences. For instance, the marginal effect and percentage change of having a first-child girl among low educated mothers are 0.09 and 4.5 percent while these numbers are 0.17 and 7.4 among high educated mothers.

Another way to look at these effects is to examine whether there are differences among birth cohorts or countries or that there are any specific sub-group in the population that drives the main results. To explore this potential heterogeneity, I show the marginal effects for different birth cohorts (born in 1925-1950, 1950-1960, 1960-1970, 1970-1980, 1980-1990, and 1990-2000) in four panels of Figure 4 for four outcomes. The effects are statistically significant for virtually all cohorts and outcomes. The interesting facet of these figures is that the marginal effects are diminishing for earlier cohorts implying that son preference fertility behavior has reduced for recent cohorts of women compared to earlier ones. Moreover, I show the marginal effects of the first-child girl on different outcomes for each individual country in four panels of Figure 5. The marginal effects are significantly larger for Cambodia, China, India, Nepal, and Vietnam. These estimates are also comparable to the previous studies that document son preference among these countries (Almond et al., 2013; Bhalotra et al., 2020; Jayachandran, 2015). 
Figure 4. Marginal Effects across Birth Coho
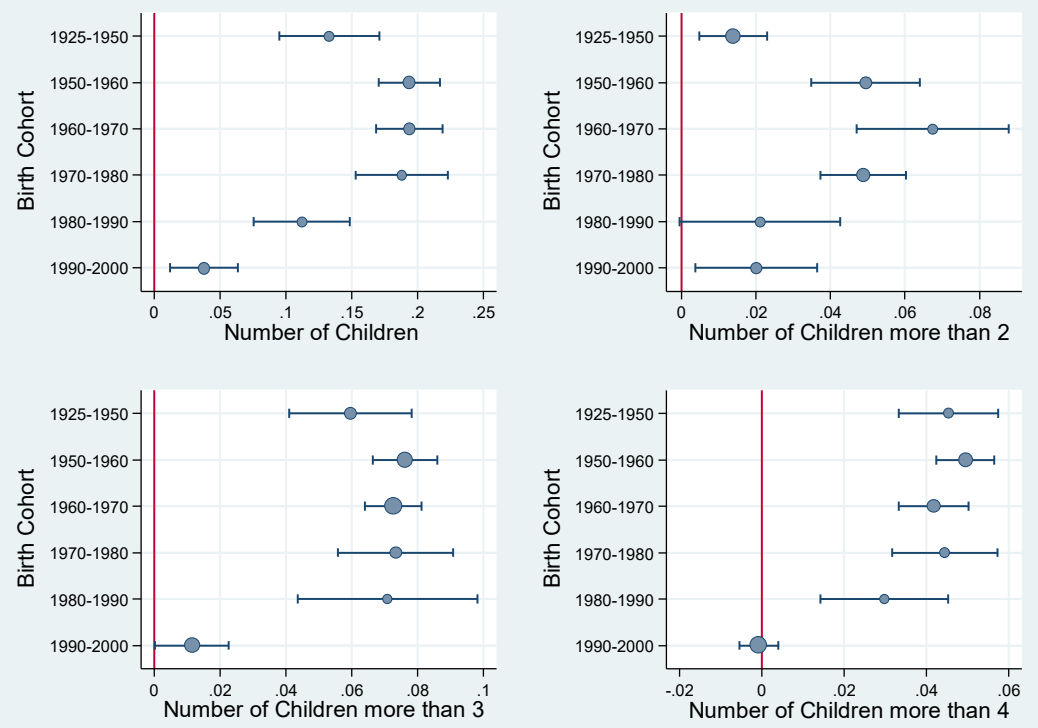

Figure 5. Marginal Effects across Countries
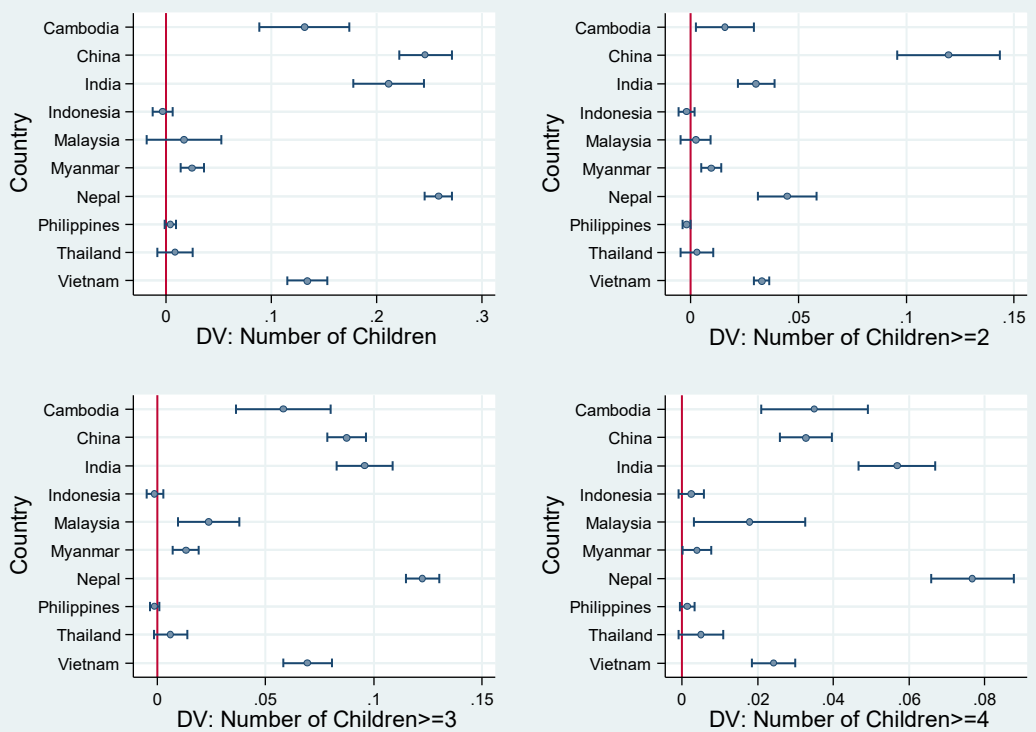

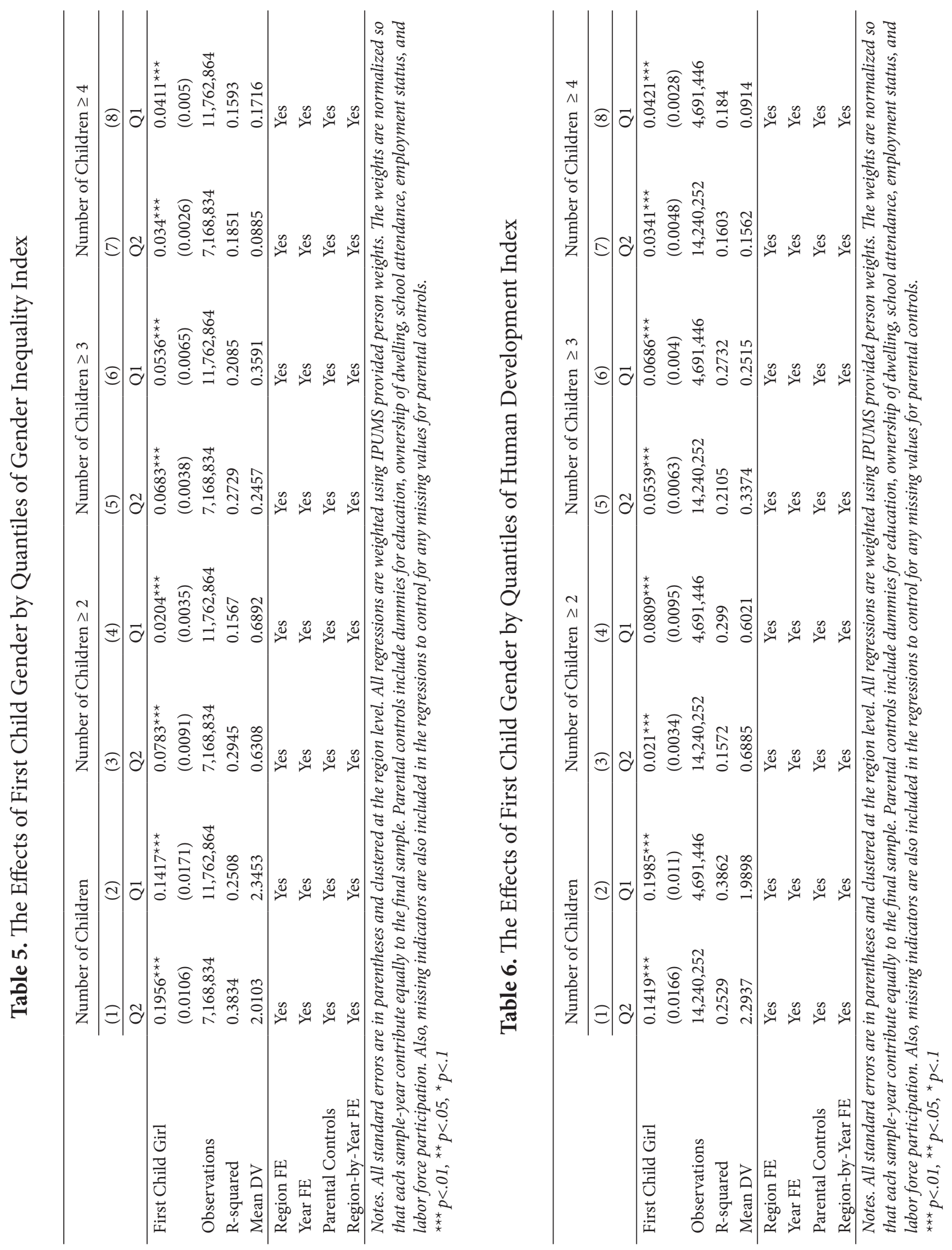

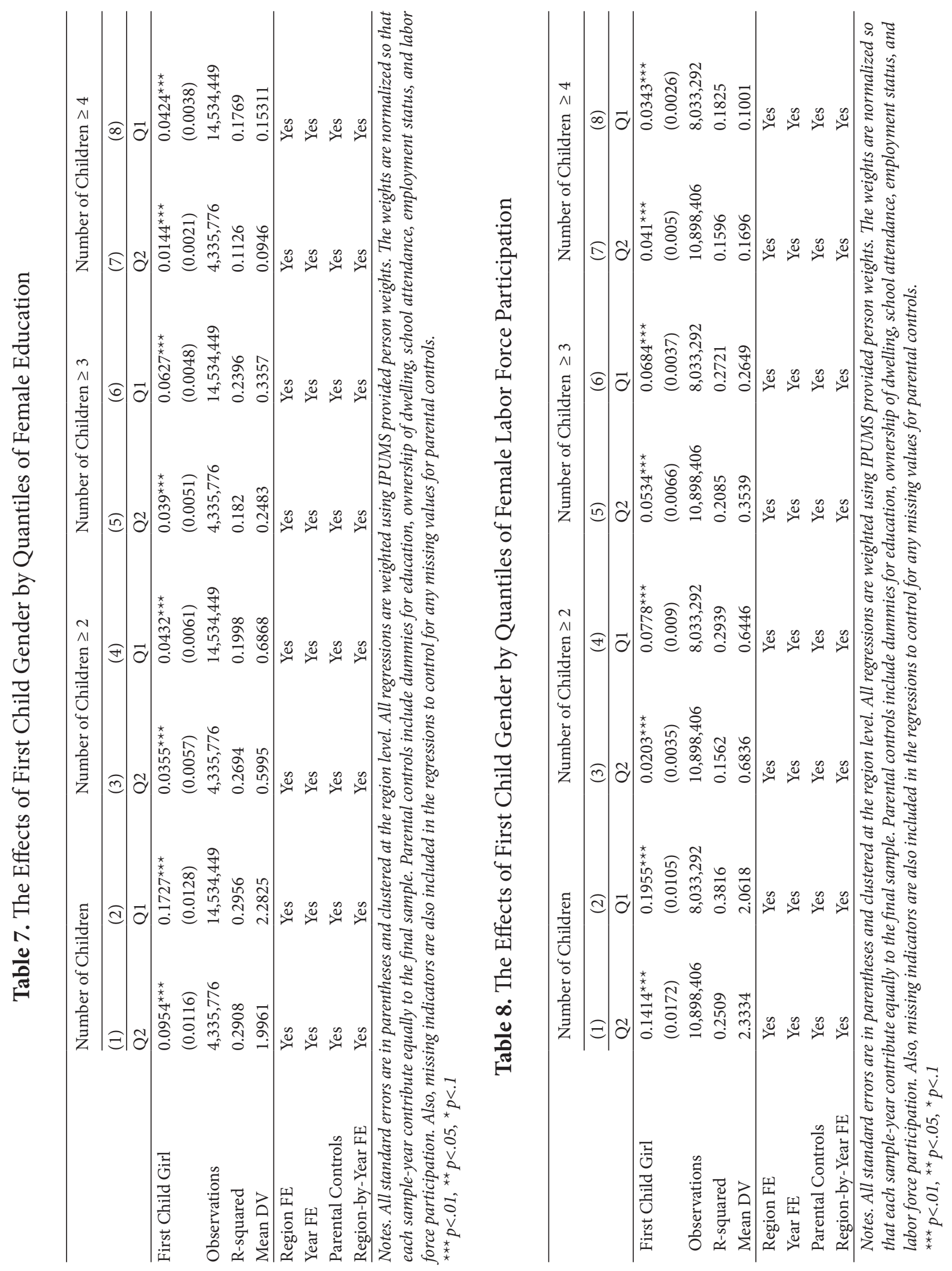


\section{CONCLUSION}

Parental gender-based behavior and son preference could start as early as antenatal period, may be reflected in sex-selective abortion, persists in resource allocation after birth, and observed in health and education investment during childhood. These gender-based attitudes could partly explain the observed gender inequality in economic and non-economic outcomes specifically in developing countries. This gender inequality could have negative effects on society in various dimensions (Forbes, 2000; Osmani \& Sen, 2003; Read \& Gorman, 2010; Seguino, 2000, 2011). Negative externalities of gender inequality call for policies to close these gaps. To this end, it is essential to understand the dynamics and magnitude of gender-based behavior among families and countries. This paper aimed to do so.

I used census data of ten South and Southeast Asian countries (Cambodia, China, India, Indonesia, Malaysia, Myanmar, Nepal, Philippines, Thailand, and Vietnam) for the years 1970-2014 to explore the son preference among families. I showed that having a first-child girl significantly increases fertility. On average, having a first-child girl is associated with a 0.16 increase in the total number of children and 4.2 percentage points higher probability of having at least two children in the household. These effects are consistent with the notion of son preference among parents who decide to have more children to have a boy when they observe the gender of the first child to be a girl.

In a series of robustness checks, I showed that the effects are robust, statistically significant, and economically comparable to the main results for the subsample of married mothers, across various specifications, birth cohorts, and within each individual country. Interestingly, I find that the marginal effects are significantly smaller for later cohorts and that the son preference aspect of fertility is diminishing over time. Moreover, the results suggest that the effects are larger for countries with higher Gender Inequality Index and lower Human Development Index. In addition, the effects are also larger for low educated females and those that are not active in the labor force. Overall, the combined evidence implies that families have discernible son preference and that they reveal this preference by increasing their fertility when they observe their child's gender to be a girl. The future research may use qualitative measures from surveys to explore whether having more children, at least partly in the people's opinion, is a response to a first-born girl or not. This kind of research could not only validate the results of this paper but also confirms the findings of a large body of the literature that explore the family structure response of having a first-born girl.

\section{DISCLOSURE STATEMENT}

The authors have no conflicts of interest to disclose.

\section{FUNDING DETAILS}

The authors received no financial support for the research, authorship, and publication of this article. 


\section{REFERENCES}

Abrevaya, J. (2009). Are there missing girls in the United States? Evidence from birth data. American Economic Journal: Applied Economics, 1(2), 1-34. https://doi.org/10.1257/app.1.2.1

Alesina, A., Giuliano, P., \& Nunn, N. (2013). On the origins of gender roles: Women and the plough. T he Quarterly Journal of Economics, 128(2), 469-530.

Almond, D., \& Edlund, L. (2008). Son-biased sex ratios in the 2000 United States Census. Proceedings of the National Academy of Sciences of the United States of America, 105(15), 5681-5682. https://doi.org/10.1073/pnas.0800703105

Almond, D., Edlund, L., \& Milligan, K. (2013). Son Preference and the Persistence of Culture: Evidence from South and East Asian Immigrants to Canada. Population and Development Review, 39(1), 75-95. https://doi.org/10.1111/j.1728-4457.2013.00574.x

Altindag, O. (2016). Son Preference, Fertility Decline, and the Nonmissing Girls of Turkey. Demography, 53(2), 541-566. https://doi.org/10.1007/s13524-016-0455-0

Anderson, S. (2007). The economics of dowry and brideprice. Journal of Economic Perspectives, 21(4), 151-174. https://doi.org/10.1257/jep.21.4.151

Andersson, G., Hank, K., Rønsen, M., \& Vikat, A. (2006). Gendering family composition: Sex preferences for children and childbearing behavior in the Nordic countries. Demography, 43(2), 255-267. https://doi.org/10.1353/dem.2006.0010

Arnold, F., Choe, M. K., \& Roy, T. K. (1998). Son preference, the family-building process and child mortality in india. Population Studies, 52(3), 301-315. https://doi.org/10.1080/0032472031000150486

Asadullah, M. N., Mansoor, N., Randazzo, T., \& Wahhaj, Z. (2021). Is son preference disappearing from Bangladesh? World Development, 140, 105353. https://doi.org/10.1016/j.worlddev.2020.105353

Azimi, E. (2015). The effect of children on female labor force participation in urban Iran. IZA Journal of Labor \& Development, 4(1), 5.

Baker, M., \& Milligan, K. (2010). Evidence from maternity leave expansions of the impact of maternal care on early child development. Journal of Human Resources, 45(1), 1-32. https://doi.org/10.3368/jhr.45.1.1

Baker, M., \& Milligan, K. (2016). Boy-girl differences in parental time investments: Evidence from three countries. Journal of Human Capital, 10(4), 399-441. https://doi.org/10.1086/688899

Barcellos, S. H., Carvalho, L. S., \& Lleras-Muney, A. (2014). Child gender and parental investments in india: Are boys and girls treated differently? American Economic Journal: Applied Economics, 6(1 A), 157-189. https://doi.org/10.1257/app.6.1.157

Bauer, P., \& Riphahn, R. T. (2007). Heterogeneity in the intergenerational transmission of educational attainment: evidence from Switzerland on natives and second-generation immigrants. Journal of Population Economics, 20(1), 121-148.

Bhalotra, S., Brulé, R., \& Roy, S. (2020). Women's inheritance rights reform and the preference for sons in India. Journal of Development Economics, 146, 102275. https://doi.org/10.1016/j.jdeveco.2018.08.001

Bhalotra, S., \& Rawlings, S. (2013). Gradients of the intergenerational transmission of health in developing countries. Review of Economics and Statistics, 95(2), 660-672. https://doi.org/10.1162/REST_a_00263

Bharadwaj, P., \& Lakdawala, L. K. (2013). Discrimination begins in the womb: Evidence of sex-selective prenatal investments. Journal of Human Resources, 48(1), 71-113. https://doi.org/10.3368/jhr.48.1.71

Bhaskar, V. (2011). Sex selection and gender balance. American Economic Journal: Microeconomics, 3(1), 214-244. https://doi.org/10.1257/mic.3.1.214 
Blau, F. D., Kahn, L. M., Brummund, P., Cook, J., \& Larson-Koester, M. (2020). Is there still son preference in the United States? Journal of Population Economics, 33(3), 709-750. https://doi.org/10.1007/s00148-019-00760-7

Boserup, E., Kanji, N., Tan, S. F., \& Toulmin, C. (2013). Woman's role in economic development. In Woman's Role in Economic Development. Taylor and Francis. https://doi.org/10.4324/9781315065892

Carranza, E. (2012). Islamic Inheritance Law, Son Preference and Fertility Behavior of Muslim Couples in Indonesia. The World Bank. https://doi.org/10.1596/1813-9450-5972

Chai Bin Park, \& Nam-Hoon Cho. (1995). Consequences of son preference in a low-fertility society: imbalance of the sex ratio at birth in Korea. Population \& Development Review, 21(1), 59-84. https://doi.org/10.2307/2137413

Chakraborty, T., \& Kim, S. (2010). Kinship institutions and sex ratios in India. Demography, 47(4), 989-1012. https://doi.org/10.1007/BF03213736

Chen, Y., Li, H., \& Meng, L. (2013). Prenatal sex selection and missing girls in China: Evidence from the diffusion of diagnostic ultrasound. Journal of Human Resources, 48(1), 36-70. https://doi.org/10.3368/jhr.48.1.36

Choi, E. J., \& Hwang, J. (2020). Transition of Son Preference: Evidence From South Korea. Demography, 57(2), 627-652. https://doi.org/10.1007/s13524-020-00863-x

Choi, E. J., \& Hwang, J. (2015). Child gender and parental inputs: No more son preference in Korea? American Economic Review, 105(5), 638-643. https://doi.org/10.1257/aer.p20151118

Dahl, G. B., \& Moretti, E. (2008). The Demand for Sons. Review of Economic Studies, 75(4), 10851120. https://doi.org/10.1111/j.1467-937X.2008.00514.x

Das Gupta, M., Jiang, Z., Li, B., Xie, Z., Woojin, C., \& Bae, H. O. (2003a). Why is son preference so persistent in East and South Asia? A cross-country study of China, India and the Republic of Korea. Journal of Development Studies, 40(2), 153-187. https://doi.org/10.1080/00220380412331293807

Das Gupta, M., Jiang, Z., Li, B., Xie, Z., Woojin, C., \& Bae, H. O. (2003b). Why is son preference so persistent in East and South Asia? A cross-country study of China, India and the Republic of Korea. Journal of Development Studies, 40(2), 153-187. https://doi.org/10.1080/00220380412331293807

Doepke, M., \& Tertilt, M. (2009). Women's Liberation: What's in It for Men? *. Quarterly Journal of Economics, 124(4), 1541-1591. https://doi.org/10.1162/qjec.2009.124.4.1541

Dribe, M., Breschi, M., Gagnon, A., Gauvreau, D., Hanson, H. A., Maloney, T. N., Mazzoni, S., Molitoris, J., Pozzi, L., Smith, K. R., \& Vézina, H. (2017). Socio-economic status and fertility decline: Insights from historical transitions in Europe and North America. Population Studies, 71(1), 3-21. https://doi.org/10.1080/00324728.2016.1253857

Duan, H., \& Hicks, D. L. (2020). New evidence on son preference among immigrant households in the United States. IZA Journal of Development and Migration, 11(1), 14.

https://doi.org/10.2478/izajodm-2020-0014

Dubuc, S., \& Coleman, D. (2007). An Increase in the Sex Ratio of Births to India-born Mothers in England and Wales: Evidence for Sex-Selective Abortion. Population and Development Review, 33(2), 383-400. https://doi.org/10.1111/j.1728-4457.2007.00173.x

Dyson, T., \& Moore, M. (1983). On kinship structure, female autonomy, and demographic behavior in India. Population \& Development Review, 9(1), 35-60. https://doi.org/10.2307/1972894

Ebenstein, A., \& Leung, S. (2010). Son Preference and Access to Social Insurance: Evidence from China's Rural Pension Program. Population and Development Review, 36(1), 47-70. https://doi.org/10.1111/j.1728-4457.2010.00317.x

Fernández, R. (2013). Cultural change as learning: The evolution of female labor force participation over a century. American Economic Review, 103(1), 472-500.

https://doi.org/10.1257/aer.103.1.472 
Fernandez, R., \& Fogli, A. (2009). Culture: An empirical investigation of beliefs, work, and fertility. American Economic Journal: Macroeconomics, 1(1), 146-177.

Fernández, R., \& Fogli, A. (2006). Fertility: The role of culture and family experience. Journal of the European Economic Association, 4(2-3), 552-561.

Forbes, K. J. (2000). A reassessment of the relationship between inequality and growth. American Economic Review, 90(4), 869-887. https://doi.org/10.1257/aer.90.4.869

Foroutan, Y., \& Ashkaran, R. (2019). Demographic and Socio-Cultural Study of Gender Preference in Iran. In Journal of Applied Sociology (Vol. 29, Issue 72). University of Isfahan. https://doi.org/10.22108/JAS.2018.104836.1134

Greenwood, J., Seshadri, A., \& Yorukoglu, M. (2005). Engines of Liberation. The Review of Economic Studies, 72(1), 109-133. https://doi.org/10.1111/0034-6527.00326

Guo, R., \& Zhang, J. (2020). The Effects of Children's Gender Composition on Filial Piety and OldAge Support*. The Economic Journal, 130(632), 2497-2525. https://doi.org/10.1093/ej/ueaa027

Hamoudi, A., \& Nobles, J. (2014). Do Daughters Really Cause Divorce? Stress, Pregnancy, and Family Composition. Demography, 51(4), 1423-1449. https://doi.org/10.1007/s13524-014-0305-x

Human Development Reports. (2020). Gender Inequality Index (GII) | Human Development Reports. http://hdr.undp.org/en/content/gender-inequality-index-gii

Hussain, R., Fikree, F. F., \& Berendes, H. W. (2000). The role of son preference in reproductive behaviour in Pakistan. Bulletin of the World Health Organization, 78(3), 379-388. https://doi.org/10.1590/S0042-96862000000300014

Ichino, A., Lindström, E. A., \& Viviano, E. (2014). Hidden consequences of a first-born boy for mothers. Economics Letters, 123(3), 274-278. https://doi.org/10.1016/j.econlet.2014.03.001

Jayachandran, S. (2015). The Roots of Gender Inequality in Developing Countries. Annual Review of Economics, 7(1), 63-88. https://doi.org/10.1146/annurev-economics-080614-115404

Jayachandran, S., \& Lleras-Muney, A. (2009). Life Expectancy and Human Capital Investments: Evidence from Maternal Mortality Declines *. Quarterly Journal of Economics, 124(1), 349397. https://doi.org/10.1162/qjec.2009.124.1.349

Junhong, C. (2001). Prenatal sex determination and sex-selective abortion in rural central China. Population and Development Review, 27(2), 259-281. https://doi.org/10.1111/j.1728-4457.2001.00259.x

Kabeer, N., Huq, L., \& Mahmud, S. (2014). Diverging Stories of "Missing Women" in South Asia: Is Son Preference Weakening in Bangladesh? Feminist Economics, 20(4), 138-163. https://doi.org/10.1080/13545701.2013.857423

Kashyap, R., \& Villavicencio, F. (2016). The Dynamics of Son Preference, Technology Diffusion, and Fertility Decline Underlying Distorted Sex Ratios at Birth: A Simulation Approach. Demography, 53(5), 1261-1281. https://doi.org/10.1007/s13524-016-0500-z

Kaushal, N., \& Muchomba, F. M. (2018). Missing time with parents: son preference among Asians in the USA. Journal of Population Economics, 31(2), 397-427. https://doi.org/10.1007/s00148-017-0668-6

Khan, M. A., \& Sirageldin, I. (1977). Son preference and the demand for additional children in pakistan. Demography, 14(4), 481-495. https://doi.org/10.2307/2060591

Kim, S., \& Lee, S. H. (2020). Son Preference and Fertility Decisions: Evidence From Spatiotemporal Variation in Korea. Demography, 57(3), 927-951. https://doi.org/10.1007/s13524-020-00875-7

Kishore, A., \& Spears, D. (2014). Having a Son Promotes Clean Cooking Fuel Use in Urban India: Women's Status and Son Preference. Economic Development and Cultural Change, 62(4), 673-699. https://doi.org/10.1086/676330 
Koolwal, G. B. (2007). Son Preference and Child Labor in Nepal: The Household Impact of Sending Girls to Work. World Development, 35(5), 881-903.

https://doi.org/10.1016/j.worlddev.2007.01.001

Kureishi, W., \& Wakabayashi, M. (2009). Son preference in Japan. Journal of Population Economics 2009 24:3, 24(3), 873-893. https://doi.org/10.1007/S00148-009-0282-3

Kureishi, W., \& Wakabayashi, M. (2011). Son preference in Japan. Journal of Population Economics, 24(3), 873-893. https://doi.org/10.1007/s00148-009-0282-3

Lei, X., Shen, Y., Smith, J. P., \& Zhou, G. (2017). Sibling gender composition's effect on education: evidence from China. Journal of Population Economics, 30(2), 569-590. https://doi.org/10.1007/s00148-016-0614-z

Li, X., Chan, M. W. L., Spencer, B. G., \& Yang, W. (2016). Does the marriage market sex ratio affect parental sex selection? Evidence from the Chinese census. Journal of Population Economics, 29(4), 1063-1082. https://doi.org/10.1007/s00148-016-0599-7

Lundberg, S. (2005). Sons, Daughters, and Parental Behaviour. Oxford Review of Economic Policy, 21(3), 340-356. https://doi.org/10.1093/oxrep/gri020

Malak, N., Rahman, M. M., \& Yip, T. A. (2019). Baby bonus, anyone? Examining heterogeneous responses to a pro-natalist policy. Journal of Population Economics, 32(4), 1205-1246. https://doi.org/10.1007/s00148-019-00731-y

Milazzo, A. (2014). Son Preference, Fertility and Family Structure: Evidence from Reproductive Behavior among Nigerian Women. The World Bank.

https://doi.org/10.1596/1813-9450-6869

Milazzo, A. (2018). Why are adult women missing? Son preference and maternal survival in India. Journal of Development Economics, 134, 467-484. https://doi.org/10.1016/j.jdeveco.2018.06.009

Miller, B. D. (1987). Female Infanticide and Child Neglect in Rural North India. In Child Survival (pp. 95-112). Springer Netherlands. https://doi.org/10.1007/978-94-009-3393-4_5

Minnesota Population Center. (2020). Integrated Public Use Microdata Series, International: Version 7.3 [dataset]. Minneapolis, MN: IPUMS. https://doi.org/https://doi.org/10.18128/D020.V7.2

Mitra, A. (2014). Son Preference in India: Implications for Gender Development. In Journal of Economic Issues (Vol. 48, Issue 4, pp. 1021-1037). Routledge. https://doi.org/10.2753/JEI0021-3624480408

Muchomba, F. M., \& Chatterji, S. (2020). Disability among children of immigrants from India and China: Is there excess disability among girls? Population Studies, 74(2), 263-281. https://doi.org/10.1080/00324728.2020.1762911

Noghani, F., \& Noghanibehambari, H. (2019). Product Market Competition, Corporate Governance, And Managerial Slack: Evidence from Trade Liberalization. Journal of Leadership, Accountability and Ethics, 16(4). https://doi.org/10.33423/jlae.v16i4.2372

NoghaniBehambari, H., Noghani, F., \& Tavassoli, N. (2020). Early Life Income Shocks and Old-Age Cause-Specific Mortality. Economic Analysis, 53(2), 1-19.

Noghanibehambari, H., \& Rahnamamoghadam, M. (2020). Is income inequality reflected in consumption inequality in Iran? Middle East Development Journal. https://doi.org/10.1080/17938120.2020.1770488

Noghanibehambari, Hamid, Noghani, F., \& Tavassoli, N. (2020). Child Support Enforcement and Child Mortality. Applied Economics Letters. https://doi.org/10.1080/13504851.2020.1869157

Noghanibehambari, Hamid, \& Salari, M. (2020). Health benefits of social insurance. Health Economics, 29(12), 1813-1822. https://doi.org/10.1002/hec.4170

Noghanibehambari, Hamid, Tavassoli, N., \& Noghani, F. (2020a). Intergenerational Transmission of Culture among First- and Second-Generation Immigrants: The Case of Age at First Birth and Nonmarital Childbirth. https://doi.org/10.13140/RG.2.2.12738.40641 
Noghanibehambari, Hamid, Tavassoli, N., \& Noghani, F. (2020b). Intergenerational transmission of culture among immigrants: Gender gap in education among first and second generations. Journal of Economics and Political Economy, 7(4), 284-318. https://doi.org/10.1453/JEPE.V7I4.2145

Odimegwu, C. O., Akinyemi, J. O., \& De Wet, N. (2017). Premarital birth, children's sex composition and marital instability among women in sub-Saharan Africa. Journal of Population Research, 34(4), 327-346. https://doi.org/10.1007/s12546-017-9193-4

Osmani, S., \& Sen, A. (2003). The hidden penalties of gender inequality: Fetal origins of ill-health. Economics and Human Biology, 1(1), 105-121. https://doi.org/10.1016/S1570-677X(02)00006-0

Oswald, A. J., \& Powdthavee, N. (2010). Daughters and left-wing voting. Review of Economics and Statistics, 92(2), 213-227. https://doi.org/10.1162/rest.2010.11436

Palloni, G. (2017). Childhood health and the wantedness of male and female children. Journal of Development Economics, 126, 19-32. https://doi.org/10.1016/j.jdeveco.2016.11.005

Pollmann-Schult, M. (2017). Sons, Daughters, and the Parental Division of Paid Work and Housework. Journal of Family Issues, 38(1), 100-123. https://doi.org/10.1177/0192513X15593577

Qian, N. (2008). Missing Women and the Price of Tea in China: The Effect of Sex-Specific Earnings on Sex Imbalance *. Quarterly Journal of Economics, 123(3), 1251-1285. https://doi.org/10.1162/qjec.2008.123.3.1251

Rao, V. (1993). The rising price of husbands: a hedonic analysis of dowry increases in rural India. Journal of Political Economy, 101(4), 666-677. https://doi.org/10.1086/261892

Read, J. G., \& Gorman, B. K. (2010). Gender and Health Inequality. Annual Review of Sociology, 36(1), 371-386. https://doi.org/10.1146/annurev.soc.012809.102535

Salari, M., Javid, R. J., \& Noghanibehambari, H. (2021). The nexus between CO2 emissions, energy consumption, and economic growth in the U.S. Economic Analysis and Policy, 69, 182-194. https://doi.org/10.1016/j.eap.2020.12.007

Seguino, S. (2000). Gender inequality and economic growth: A cross-country analysis. World Development, 28(7), 1211-1230. https://doi.org/10.1016/S0305-750X(00)00018-8

Seguino, S. (2011). Gender inequality and economic growth: A reply to schober and winter-ebmer. World Development, 39(8), 1485-1487. https://doi.org/10.1016/j.worlddev.2011.05.002

Suarez, P. A. (2018). Child-bride marriage and female welfare. European Journal of Law and Economics, 45(1), 1-28. https://doi.org/10.1007/s10657-017-9562-7

Sun, A., Zhang, C., \& Hu, X. (2019). Boys, Girls, and Grandparents: The Impact of the Sex of Preschool-Aged Children on Family Living Arrangements and Maternal Labor Supply. Demography, 56(3), 813-833. https://doi.org/10.1007/s13524-019-00783-5

Toranji, M., Noghanibehambari, H., Noghani, F., \& Tavassoli, N. (2020). A Game Theoretic Approach in Bidding Strategy in Iran Wholesale Electricity Market. Journal of Applied Business and Economics, 22(11). https://doi.org/10.33423/jabe.v22i11.3749

Wang, S.-C., Sung, W.-W., Kao, Y.-L., Hsieh, T.-Y., Chen, W.-J., Chen, S.-L., \& Chang, H.-R. (2017). The gender difference and mortality-to-incidence ratio relate to health care disparities in bladder cancer: National estimates from 33 countries. Scientific Reports, 7(1), 4360.

World Bank. (2020). GDP per capita (current US\$)|Data. https://data.worldbank.org/indicator/NY.GDP.PCAP.CD

Yamamura, E. (2013). Effects of sex preference and social pressure on fertility in changing Japanese families. Journal ofSocio-Economics, 46, 97-104. https://doi.org/10.1016/j.socec.2013.08.002

Yoo, S. H., Hayford, S. R., \& Agadjanian, V. (2017). Old Habits Die Hard? Lingering Son Preference in an Era of Normalizing Sex Ratios at Birth in South Korea. Population Research and Policy Review, 36(1), 25-54. https://doi.org/10.1007/s11113-016-9405-1

Zaidi, B., \& Morgan, S. P. (2016). In the Pursuit of Sons: Additional Births or Sex-Selective Abortion in Pakistan? Population and Development Review, 42(4), 693-710. https://doi.org/10.1111/ padr.12002 


\section{AppendixA}

Appendix Table A-1- Cross Tabulation of the Final Sample by Year

\begin{tabular}{|c|c|c|c|}
\hline Year & Freq. & Percent & Cum. \\
\hline 1970 & 90649 & 0.48 & 0.48 \\
\hline 1971 & 73861 & 0.39 & 0.87 \\
\hline 1976 & 31148 & 0.16 & 1.03 \\
\hline 1980 & 918183 & 4.85 & 5.88 \\
\hline 1982 & 1067811 & 5.64 & 11.52 \\
\hline 1983 & 74980 & 0.40 & 11.92 \\
\hline 1985 & 73060 & 0.39 & 12.31 \\
\hline 1987 & 81533 & 0.43 & 12.74 \\
\hline 1989 & 305164 & 1.61 & 14.35 \\
\hline 1990 & 2362576 & 12.48 & 26.83 \\
\hline 1991 & 36773 & 0.19 & 27.02 \\
\hline 1993 & 71689 & 0.38 & 27.40 \\
\hline 1995 & 784227 & 4.14 & 31.54 \\
\hline 1998 & 132184 & 0.70 & 32.24 \\
\hline 1999 & 394814 & 2.09 & 34.33 \\
\hline 2000 & 5004392 & 26.43 & 60.76 \\
\hline 2001 & 262631 & 1.39 & 62.15 \\
\hline 2004 & 89733 & 0.47 & 62.62 \\
\hline 2005 & 136770 & 0.72 & 63.34 \\
\hline 2008 & 143556 & 0.76 & 64.10 \\
\hline 2009 & 1913132 & 10.11 & 74.21 \\
\hline 2010 & 3932511 & 20.77 & 94.98 \\
\hline 2011 & 417794 & 2.21 & 97.18 \\
\hline 2013 & 14544 & 0.08 & 97.26 \\
\hline 2014 & 518490 & 2.74 & 100.00 \\
\hline Total & $18,932,205$ & 100.00 & \\
\hline
\end{tabular}


Appendix Table A-2 - Summary Statistics for Countries Below Median gender Inequality Index

\begin{tabular}{|c|c|c|c|c|c|}
\hline Variable & Observations & Mean & Std. Dev. & Min & Max \\
\hline Number of Children & $7,168,834$ & 2.0103 & 1.0712 & 1 & 9 \\
\hline Age & $7,168,834$ & 32.4594 & 5.9478 & 18 & 45 \\
\hline Birth Cohort & $7,168,834$ & 1963.8069 & 11.2218 & 1925 & 1991 \\
\hline Age of Eldest Child & $7,168,834$ & 9.1784 & 5.1469 & 1 & 18 \\
\hline Sex of First Child (girl=1) & $7,168,834$ & .4852 & .4998 & 0 & 1 \\
\hline Dwelling: Owned & $7,168,834$ & .3162 & .465 & 0 & 1 \\
\hline Dwelling: Rented & $7,168,834$ & .0228 & .1494 & 0 & 1 \\
\hline Dwelling: Missing & $7,168,834$ & .6609 & .4734 & 0 & 1 \\
\hline Father Absent & $7,168,834$ & .0286 & .1666 & 0 & 1 \\
\hline School Attending & $7,168,834$ & .0029 & .0537 & 0 & 1 \\
\hline Ever School Attended & $7,168,834$ & .5492 & .4976 & 0 & 1 \\
\hline Education less than Secondary & $7,168,834$ & .8642 & .3426 & 0 & 1 \\
\hline Education Secondary University & $7,168,834$ & .1351 & .3418 & 0 & 1 \\
\hline Education Missing & $7,168,834$ & .0008 & .0275 & 0 & 1 \\
\hline Is Employed & $7,168,834$ & .6353 & .4813 & 0 & 1 \\
\hline Employment Missing & $7,168,834$ & .2697 & .4438 & 0 & 1 \\
\hline Labor Force Participation & $7,168,834$ & .6402 & .4799 & 0 & 1 \\
\hline Labor Force Missing & $7,168,834$ & .2697 & .4438 & 0 & 1 \\
\hline Number of Children $\geq 2$ & $7,168,834$ & .6309 & .4826 & 0 & 1 \\
\hline Number of Children $\geq 3$ & $7,168,834$ & .2457 & .4305 & 0 & 1 \\
\hline Number of Children $\geq 4$ & $7,168,834$ & .0886 & .2841 & 0 & 1 \\
\hline GDP per Capita & $7,168,834$ & 2279.2499 & 1159.9153 & 1018.1211 & 7974.251 \\
\hline Gender Inequality Index & $7,168,834$ & .22 & .0655 & .168 & .359 \\
\hline Maternal Mortality Rate & $7,168,834$ & 34.1056 & 6.6186 & 29 & 43 \\
\hline \%Secondary Education & $7,168,834$ & 71.5334 & 6.8891 & 43.5 & 76 \\
\hline $\begin{array}{l}\text { Female Labor Force } \\
\text { Participation Rate }\end{array}$ & $7,168,834$ & 64.5124 & 6.0796 & 50.7 & 72.7 \\
\hline
\end{tabular}


Appendix Table A-3 - Summary Statistics for Countries Above Median gender Inequality Index

\begin{tabular}{|c|c|c|c|c|c|}
\hline Variable & Observations & Mean & Std. Dev. & Min & Max \\
\hline Number of Children & $11,763,371$ & 2.3453 & 1.3533 & 1 & 9 \\
\hline Age & $11,763,371$ & 31.5857 & 6.458 & 18 & 45 \\
\hline Birth Cohort & $11,763,371$ & 1970.0115 & 11.1051 & 1926 & 1996 \\
\hline Age of Eldest Child & $11,763,371$ & 9.1901 & 5.0927 & 1 & 18 \\
\hline Sex of First Child (girl=1) & $11,763,371$ & .4795 & .4996 & 0 & 1 \\
\hline Dwelling: Owned & $11,763,371$ & .5641 & .4959 & 0 & 1 \\
\hline Dwelling: Rented & $11,763,371$ & .136 & .3428 & 0 & 1 \\
\hline Dwelling: Missing & $11,763,371$ & .2999 & .4582 & 0 & 1 \\
\hline Father Absent & $11,763,371$ & .0517 & .2215 & 0 & 1 \\
\hline School Attending & $11,763,371$ & .0169 & .1289 & 0 & 1 \\
\hline Ever School Attended & $11,763,371$ & .3871 & .4871 & 0 & 1 \\
\hline $\begin{array}{l}\text { Education less than } \\
\text { Secondary }\end{array}$ & $11,763,371$ & .709 & .4542 & 0 & 1 \\
\hline $\begin{array}{l}\text { Education Secondary } \\
\text { University }\end{array}$ & $11,763,371$ & .2863 & .452 & 0 & 1 \\
\hline Education Missing & $11,763,371$ & .0048 & .0688 & 0 & 1 \\
\hline Is Employed & $11,763,371$ & .2624 & .44 & 0 & 1 \\
\hline Employment Missing & $11,763,371$ & .4249 & .4943 & 0 & 1 \\
\hline Labor Force Participation & $11,763,371$ & .3011 & .4588 & 0 & 1 \\
\hline Labor Force Missing & $11,763,371$ & .4249 & .4943 & 0 & 1 \\
\hline Number of Children $\geq 2$ & $11,763,371$ & .6892 & .4628 & 0 & 1 \\
\hline Number of Children $\geq 3$ & $11,763,371$ & .3591 & .4797 & 0 & 1 \\
\hline Number of Children $\geq 4$ & $11,763,371$ & .1716 & .377 & 0 & 1 \\
\hline GDP per Capita & $11,763,371$ & 2055.9494 & 677.8493 & 500.2064 & 2524.2224 \\
\hline Gender Inequality Index & $11,763,371$ & .4656 & .022 & .43 & .488 \\
\hline Maternal Mortality Rate & $11,763,371$ & 164.3038 & 31.0137 & 121 & 250 \\
\hline \%Secondary Education & $11,763,371$ & 50.8359 & 16.3647 & 15.1 & 75.6 \\
\hline $\begin{array}{l}\text { Female Labor Force } \\
\text { Participation Rate }\end{array}$ & $11,763,371$ & 52.147 & 10.8541 & 20.5 & 82.8 \\
\hline
\end{tabular}


Appendix Table A-4 - Cross Tabulation by Birth Cohort

\begin{tabular}{|c|c|c|c|}
\hline Birth Cohort & Freq. & Percent & Cum. \\
\hline 1925 & 1196 & 0.01 & 0.01 \\
\hline 1926 & 3022 & 0.02 & 0.02 \\
\hline 1927 & 1908 & 0.01 & 0.03 \\
\hline 1928 & 2572 & 0.01 & 0.05 \\
\hline 1929 & 3217 & 0.02 & 0.06 \\
\hline 1930 & 3782 & 0.02 & 0.08 \\
\hline 1931 & 7464 & 0.04 & 0.12 \\
\hline 1932 & 4905 & 0.03 & 0.15 \\
\hline 1933 & 6070 & 0.03 & 0.18 \\
\hline 1934 & 6350 & 0.03 & 0.21 \\
\hline 1935 & 34906 & 0.18 & 0.40 \\
\hline 1936 & 19109 & 0.10 & 0.50 \\
\hline 1937 & 30173 & 0.16 & 0.66 \\
\hline 1938 & 38737 & 0.20 & 0.86 \\
\hline 1939 & 37038 & 0.20 & 1.06 \\
\hline 1940 & 81318 & 0.43 & 1.49 \\
\hline 1941 & 57480 & 0.30 & 1.79 \\
\hline 1942 & 67724 & 0.36 & 2.15 \\
\hline 1943 & 71734 & 0.38 & 2.53 \\
\hline 1944 & 76482 & 0.40 & 2.93 \\
\hline 1945 & 161470 & 0.85 & 3.79 \\
\hline 1946 & 120396 & 0.64 & 4.42 \\
\hline 1947 & 132515 & 0.70 & 5.12 \\
\hline 1948 & 158694 & 0.84 & 5.96 \\
\hline 1949 & 159192 & 0.84 & 6.80 \\
\hline 1950 & 267591 & 1.41 & 8.21 \\
\hline 1951 & 220171 & 1.16 & 9.38 \\
\hline 1952 & 261883 & 1.38 & 10.76 \\
\hline 1953 & 289248 & 1.53 & 12.29 \\
\hline 1954 & 288183 & 1.52 & 13.81 \\
\hline 1955 & 456516 & 2.41 & 16.22 \\
\hline 1956 & 367131 & 1.94 & 18.16 \\
\hline 1957 & 389330 & 2.06 & 20.22 \\
\hline 1958 & 404846 & 2.14 & 22.36 \\
\hline 1959 & 362024 & 1.91 & 24.27 \\
\hline 1960 & 475722 & 2.51 & 26.78 \\
\hline 1961 & 382042 & 2.02 & 28.80 \\
\hline 1962 & 430715 & 2.28 & 31.07 \\
\hline 1963 & 536379 & 2.83 & 33.91 \\
\hline 1964 & 527584 & 2.79 & 36.69 \\
\hline 1965 & 678200 & 3.58 & 40.28 \\
\hline 1966 & 611645 & 3.23 & 43.51 \\
\hline 1967 & 548630 & 2.90 & 46.40 \\
\hline 1968 & 591893 & 3.13 & 49.53 \\
\hline 1969 & 620433 & 3.28 & 52.81 \\
\hline 1970 & 714867 & 3.78 & 56.58 \\
\hline 1971 & 656218 & 3.47 & 60.05 \\
\hline 1972 & 616763 & 3.26 & 63.31 \\
\hline 1973 & 644368 & 3.40 & 66.71 \\
\hline 1974 & 586257 & 3.10 & 69.81 \\
\hline 1975 & 628279 & 3.32 & 73.13 \\
\hline 1976 & 585136 & 3.09 & 76.22 \\
\hline 1977 & 507359 & 2.68 & 78.90 \\
\hline 1978 & 470018 & 2.48 & 81.38 \\
\hline 1979 & 466244 & 2.46 & 83.84 \\
\hline 1980 & 464305 & 2.45 & 86.29 \\
\hline 1981 & 420521 & 2.22 & 88.52 \\
\hline 1982 & 353622 & 1.87 & 90.38 \\
\hline 1983 & 349072 & 1.84 & 92.23 \\
\hline 1984 & 302763 & 1.60 & 93.83 \\
\hline 1985 & 276836 & 1.46 & 95.29 \\
\hline 1986 & 244040 & 1.29 & 96.58 \\
\hline 1987 & 189990 & 1.00 & 97.58 \\
\hline 1988 & 151140 & 0.80 & 98.38 \\
\hline 1989 & 121299 & 0.64 & 99.02 \\
\hline 1990 & 81690 & 0.43 & 99.45 \\
\hline 1991 & 54059 & 0.29 & 99.74 \\
\hline 1992 & 26718 & 0.14 & 99.88 \\
\hline 1993 & 10373 & 0.05 & 99.93 \\
\hline 1994 & 7560 & 0.04 & 99.97 \\
\hline 1995 & 3048 & 0.02 & 99.99 \\
\hline 1996 & 2040 & 0.01 & 100.00 \\
\hline Total & $18,932,205$ & 100.00 & \\
\hline
\end{tabular}


Appendix Table A-5 - Robustness of the Main Results to Different Clustering level of Standard Errors

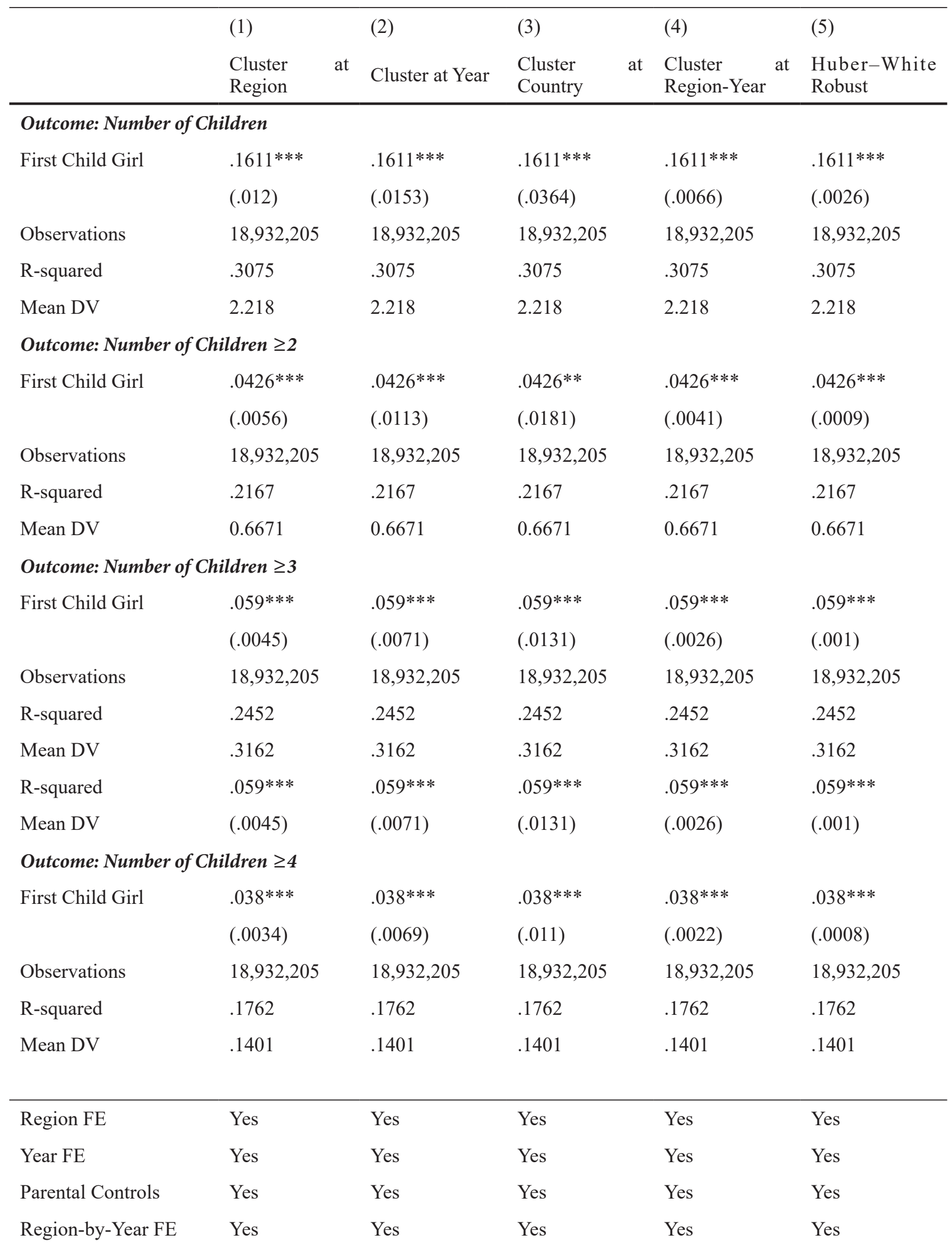

Notes. All standard errors are in parentheses and clustered at the region level. All regressions are weighted using IPUMS provided person weights. The weights are normalized so that each sample-year contribute equally to the final sample. Parental controls include dummies for education, ownership of dwelling, school attendance, employment status, and labor force participation. Also, missing indicators are also included in the regressions to control for any missing values for parental controls

${ }^{* * *} p<.01,{ }^{* *} p<.05,{ }^{*} p<.1$ 


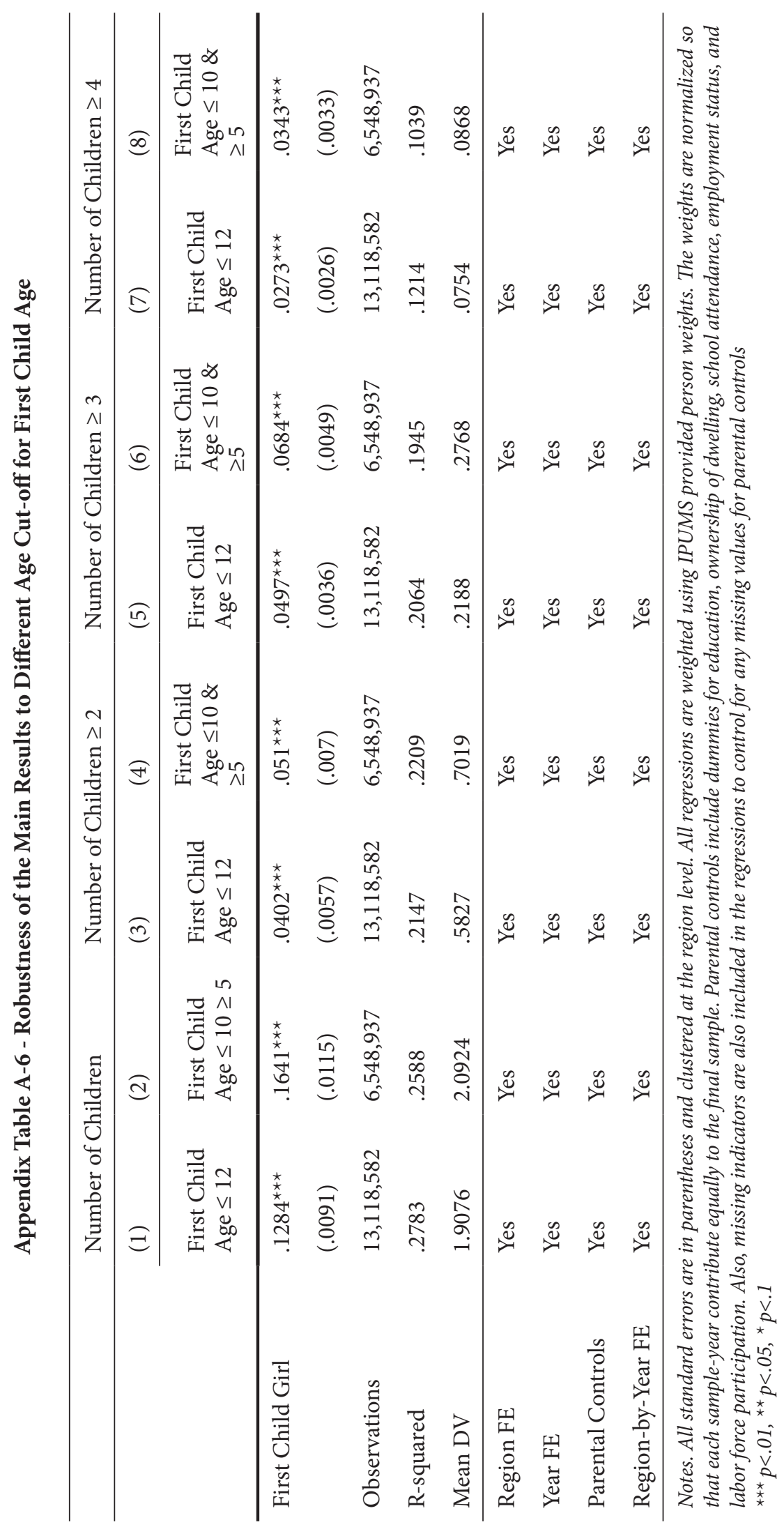

